\title{
Vorwort des Rektors
}

Ein Jahrbuch ist wie ein Kaleidoskop: Es zeigt in bunter Mischung faszinierende Neuigkeiten. Im Jahrbuch der Heinrich-Heine-Universität Düsseldorf stellen sich die neuen Köpfe vor, und bekannte Leistungsträger präsentieren uns die Facetten ihrer jüngsten wissenschaftlichen Erkenntnisse. Die Autoren bemühen sich, ihre Forschungsthemen allgemeinverständlich darzustellen. Das kann nicht immer und für jeden Leser gelingen, da manche Fachthemen doch sehr spezielle Vorkenntnisse erfordern. Das Jahrbuch ist ein Angebot für jeden an der Universität Interessierten, sich Passendes herauszusuchen. Bei mehr als 900 Seiten Umfang wird dies zweifellos gelingen.

Mit dem Jahrbuch bedankt sich die Heinrich-Heine-Universität auch bei ihren vielen Freunden und Gönnern für die ihr zuteilgewordene Unterstützung. Die Universität in der Landeshauptstadt und Wirtschaftsmetropole Düsseldorf verdankt in ihrer Entwicklung vieles der anhaltenden Zuwendung von Stadt, Region und den Ehemaligen der Universität. Herrn Univ.-Prof. em. Dr. Hans Süssmuth, der auch das diesjährige Jahrbuch konzipiert und redaktionell betreut hat, danken die Mitglieder der Universitätsleitung ganz persönlich.

Düsseldorf, im Januar 2010

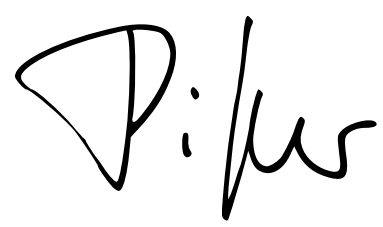

Univ.-Prof. Dr. Dr. H. Michael Piper 
